\title{
Modelos de tomada de decisão no processo orçamentário brasileiro: uma agenda de pesquisas
}

Welles Matias de Abreu, Vinícius Mendonça Neiva e Nerylson Lima

\section{Introdução}

A gestão governamental brasileira passou por diversas mudanças nas últimas décadas, buscando principalmente o aumento da eficiência dos fatores de produção e da qualidade dos serviços prestados, com vistas a promover a transição da gestão patrimonial e burocrática da administração pública para a gerencial. Pode-se citar como exemplo a introdução das inovações provenientes da Reforma Gerencial do Orçamento (RGO), implantada em 2000, que permitiu, no momento da elaboração estratégica do programa orçamentário, a melhor incorporação das prioridades de governo, observando as necessidades que precisavam ser supridas (ABREu e GOMES, 2010; Bresser-Pereira, 1996; Abrucio e Costa, 1998; Garcia, 2000).

No entanto, as referidas mudanças precisam ser continuadas e, para tanto, estudos sobre o tema orçamentário precisam ser fomentados. Recentemente, com base na análise do processo decisório (sob uma ótica multivariada e multiparadigmática) relativo à $\mathrm{RGO}$, objetivando entender pioneiramente a 
dinâmica orçamentária brasileira a partir de uma perspectiva não tradicional (como um instrumento fiscal ou mitigador ou não de conflitos distributivos), pode-se concluir pela necessidade de estímulo à continuidade de realização de estudos com finalidade de buscar compreender melhor os processos decisórios no setor público (Barcelos e Calmon, 2009).

A continuação dos estudos sobre o processo orçamentário brasileiro, sob a perspectiva do processo decisório, tem como cerne do estímulo a questão levantada por V. O. Key Jr. (1940), "'em que base deveria ser decidido alocar ' $\mathrm{X}$ ' dólares na atividade 'A' em vez da atividade 'B'?'.

Nesse sentido, o presente trabalho tem como objetivo geral identificar uma agenda de pesquisa na área orçamentária brasileira. Os objetivos específicos são: destacar os principais conceitos dos modelos de estudos do processo decisório incremental, do julgamento serial, dos fluxos múltiplos (MS) e do equilíbrio pontuado (terremoto); incentivar a realização de estudos inéditos no tocante à associação do processo orçamentário brasileiro ao processo decisório, ao sugerir temas e perguntas para linhas de pesquisas; além de contribuir na construção da resposta à supracitada questão levantada por V. O. Key Jr., trazendo considerações empíricas, porém sem ter necessariamente a pretensão de testá-las.

Para tanto, inicialmente, apresentamse as considerações sobre os aspectos metodológicos da presente pesquisa. Em seguida, o referencial teórico sobre o orçamento público brasileiro, incrementalismo, julgamento serial, fluxos múltiplos (MS) e equilíbrio pontuado (terremoto), com a descrição dos principais conceitos, variáveis e estratégias dos referidos modelos. Depois, são analisados comparativamente os seus principais componentes. Por fim, em considerações finais, são expostas sugestões de temas e perguntas para linhas de pesquisas geradas pela aplicação dos modelos à realidade orçamentária brasileira.

\section{Aspectos metodológicos}

O delineamento metodológico da presente pesquisa buscará, preliminarmente, sob a égide da racionalidade limitada, dar suporte para a análise comparativa dos principais componentes dos modelos de estudos do processo decisório incremental, do julgamento serial, dos fluxos múltiplos (MS) e do equilibrio pontuado (terremoto), para identificar os pontos comuns e as diferenças entre os referidos modelos, conforme os critérios descritos no Quadro 1.

$\mathrm{Na}$ sequência, são apresentadas informações sobre as propostas orçamentárias de 2004 a 2010 (encaminhadas pelo Poder Executivo para o Legislativo), referentes às esferas fiscal e da seguridade social, excluídos pagamentos com amortizações e juros da dívida pública correspondentes aos grupos de natureza de despesas (GND) 2 e 6, atualizados pelo Índice Nacional de Preços ao Consumidor (IPCA) do Instituto Brasileiro de Geografia e Estatística (IBGE).

São levantadas, ainda, as inclusões e as exclusões de programas orçamentários, as frequências das variações entre os exercícios, além da série histórica anual das médias com seus intervalos e desviospadrões ao longo dos anos do Plano Plurianual (PPA) vigente e anterior. Posteriormente, são realizadas análises associando os supracitados modelos com o processo orçamentário, com o intuito de identificar sugestões de temas e perguntas para linhas de pesquisas geradas pela aplicação dos modelos à realidade orçamentária brasileira. 
Quadro 1: Modelo de análise comparada das características dos modelos de estudos do processo decisório

\begin{tabular}{|c|c|c|c|c|}
\hline Característica & Incrementalismo & $\begin{array}{l}\text { Julgamento } \\
\text { serial }\end{array}$ & $\begin{array}{l}\text { Fluxos } \\
\text { múltiplos }\end{array}$ & $\begin{array}{l}\text { Equilíbrio } \\
\text { pontuado }\end{array}$ \\
\hline $\begin{array}{l}\text { Processamento } \\
\text { de informações }\end{array}$ & \multicolumn{4}{|c|}{ Detalha como são processadas as informações. } \\
\hline $\begin{array}{l}\text { Tipo de decisão e } \\
\text { ambiente }\end{array}$ & \multicolumn{4}{|c|}{$\begin{array}{l}\text { Ilustra como cada modelo trata o processo decisório, bem como em que } \\
\text { ambiente são tomadas as decisões. }\end{array}$} \\
\hline $\begin{array}{c}\text { Elementos e } \\
\text { características } \\
\text { essenciais }\end{array}$ & \multicolumn{4}{|c|}{ Detalha quais características são consideradas essenciais ao modelo. } \\
\hline Foco & \multicolumn{4}{|c|}{ Descreve qual o foco e o propósito do modelo. } \\
\hline $\begin{array}{c}\text { Atenção, agenda e } \\
\text { formato } \\
\text { da curva de } \\
\text { distribuição }\end{array}$ & \multicolumn{4}{|c|}{$\begin{array}{l}\text { Ilustra como o modelo aborda questões de atenção, definição de agenda e formato } \\
\text { das curvas de distribuição. }\end{array}$} \\
\hline $\begin{array}{c}\text { Natureza } \\
\text { do processo } \\
\text { orçamentário }\end{array}$ & \multicolumn{4}{|c|}{ Demonstra como cada modelo aborda o processo orçamentário. } \\
\hline
\end{tabular}

Fonte: Elaboração própria

\section{Referencial teórico}

\section{Orçamento público brasileiro}

A Constituição de 1988 introduziu várias mudanças significativas nos instrumentos orçamentários brasileiros, tendo destaque a obrigatoriedade para a elaboração do PPA (planejamento de médio prazo: quatro anos) e da Lei Orçamentária Anual (LOA) - considerada como de curto prazo: anual -, tendo como referência as metas e prioridades estabelecidas na Lei de Diretrizes Orçamentárias (LDO) (ABREU e Gomes, 2010). Apresenta-se, a seguir, o Quadro 2 com a descrição da finalidade de cada instrumento orçamentário.

O processo orçamentário brasileiro, recentemente, foi muito influenciado pelas perspectivas internacionais - principalmente em virtude da crise financeira ocorrida por volta dos anos 1980 e 1990 com vistas a promover uma administração pública enxuta, mais efetiva e eficiente nos governos, como forma de garantir a mínima governabilidade e proceder a uma ampla reforma do aparelho do estado patrimonial e burocrático para o modelo gerencial (Core, 2004; Garcia, 2000; Abreu e Gomes, 2010). No Brasil, a RGO teve como pontos-chave para a sua implementação mudanças com fins gerenciais no processo orçamentário (BARCELOS, 2008; Dagnino, 2002), em especial no processo de elaboração do PPA e da LOA, bem como no processo decisório (BARCELOS e Calmon, 2009).

\section{A racionalidade do processo decisório}

Os estudos neoclássicos sobre a análise orçamentária sugerem que a formulação do processo de tomada de decisão ocorre sob o preceito de racionalidade pura, em que os tomadores de decisão buscam maximizar suas utilidades e o fazem baseados em regras técnicas, a partir de 
Quadro 2: Finalidades do PPA, da LOA e da LDO

\begin{tabular}{|l|l|}
\hline Instrumento & Finalidade \\
\hline PPA & $\begin{array}{l}\text { Estabelecer, de forma regionalizada, as diretrizes, os objetivos e metas } \\
\text { da administração pública federal para as despesas de capital e outras } \\
\text { delas decorrentes, e para as relativas aos programas de natureza continu } \\
\text { ada (para quatro anos, início no segundo ano de governo e término no } \\
\text { primeiro ano do governo subsequente). }\end{array}$ \\
\hline LOA & $\begin{array}{l}\text { Compreender o orçamento fiscal referente aos Poderes da União, seus } \\
\text { fundos, órgãos e entidades da administração direta e indireta, inclusive } \\
\text { fundações instituídas e mantidas pelo poder público; o orçamento de } \\
\text { investimento das empresas em que a União, direta ou indiretamente, } \\
\text { detenha a maioria do capital social com direito a voto; e o orçamento da } \\
\text { seguridade social, abrangendo todas as entidades e órgãos a ela vincu- } \\
\text { lados, da administração direta ou indireta, bem como os fundos e fun- } \\
\text { dações instituídos e mantidos pelo poder público (anual). }\end{array}$ \\
\hline Compreender as metas e prioridades da administração pública federal, \\
incluindo as despesas de capital para o exercício financeiro subsequente, \\
orientar a elaboração da LOA, dispor sobre as alterações na legislação \\
tributária e estabelecer a política de aplicação das agências financeiras \\
oficiais de fomento (anual).
\end{tabular}

Fonte: CORE, 2007

todas as informações possíveis e de uma análise sistemática e completa das alternativas existentes e da comparação entre elas (MArch, 1994). Em outra perspectiva, o processo de decisão sob racionalidade pura e sob uma ótica das preferências do tomador de decisão antecipa as consequências futuras, a partir das decisões possíveis a serem tomadas no presente (DAvis et al., 1966).

O modelo de racionalidade pura foi muito questionado por diversos autores como Lindblom, Simon, Wildavsky, entre outros. A aplicação da racionalidade pura encontra dificuldades na identificação, compreensão e resolução dos problemas, assim como na obtenção de todas as informações possíveis (SIMON, 1979). GreEN e Thompson (2001) comentam que uma teoria permanece válida enquanto as evidências não possam refutá-la e que, diante dos fatos, é impossível ser puramente racional, opinião compartilhada por Lindblom, o que inviabiliza a adoção do modelo com racionalidade pura (MARCH, 1994; Simon, 1979). Assim sendo, a racionalidade pura não consegue ser averiguada, o que sugere que a tomada de decisão está associada à racionalidade limitada, na qual a busca por alternativas de decisão tem como alvo objetivos satisfatórios e não maximizadores (Jones, 2003), embora os tomadores de decisão acreditem estar atuando como maximizadores (BARCELOS, 2008).

O modelo de tomada de decisão baseado na racionalidade limitada, proposto por Simon (1979), March (1994) e Barcelos (2008), pressupunha ambiguidade de problemas, dificuldades para obtenção das informações (informações incompletas), limitações relativas ao tempo, 
às competências e aos recursos. Lindblom foi pioneiro em sugerir que as escolhas políticas seguem um padrão sequencial e incremental, a partir de uma situação já existente, em que a análise é conscientemente incompleta e o ambiente, limitado (Dagnino, 2002; Green e Thompson, 2001; MARCH, 1994; SimON, 1979).

\section{Modelo incremental}

A análise incremental ou incrementalismo sugerido por Lindblom é uma abordagem ampla relacionada à teoria da decisão, mas sua lógica foi estendida ao contexto orçamentário a partir das suposições de Wildavsky, de que se o processo orçamentário é baseado em políticas incrementais, então o orçamento também é incremental. Nesse contexto, as decisões orçamentárias são tomadas em um ambiente de redução de custos informacionais e com base em decisões tomadas anteriormente (FOSCHER, 2007). De acordo com Wildavsky e Caiden, essa característica decorre da complexidade do processo e das dificuldades em responder ao questionamento alocativo levantado por V. O. Key (Green e Thompson, 2001).

A proposição de Wildavsky, além de ser uma aplicação do modelo de racionalidade limitada de Simon (Swain e Hartley JR. 2001), é considerada inovadora ao relacionar o processo orçamentário com atitudes comportamentais. As bases do incrementalismo foram desenvolvidas nos estudos de Wildavsky em Politics of the Budgetary Process, publicado em 1964, e New Politics of the Budgetary Process, publicado em 1988. Ademais, em um estudo realizado por Davis, Dempster e Wildavsky (1955) sobre o orçamento dos Estados Unidos da América, os autores sugeriram que as decisões alocativas são baseadas na experiência passada, compactuando com as suposições levantadas por Simon (1979) e March (1994), além de apresentarem relações lineares, estáveis e pressuporem a necessidade de confiança entre os atores do processo. Para Wildavsky, o comportamento do processo orçamentário é considerado incremental apenas em ambientes estáveis (Swain e HarTLEY JR, 2001) e seu surgimento decorre da complexidade do processo orçamentário. As dificuldades encontradas na questão alocativa tornam a

$\quad$ “... necessita-se
investigar o papel
das avaliações
sobre os
programas e de
que forma o
processamento das
informações está
exercendo
influência sobre o
quantitativo de
programas.”

estabilidade uma característica fundamental do modelo. Igualmente, o incrementalismo possui características essenciais, entre as quais o contexto organizacional do processo decisório, a definição clara e estável dos papéis dos atores e o caráter coletivo das decisões, o que caracteriza o processo decisório como um processo social. Em outras palavras, 
as decisões orçamentárias são políticas e, sendo assim, incluem aspectos políticos, administrativos, econômicos e sociais (Silva, 1988; Swain e Hartley JR., 2001).

O incrementalismo pressupõe que a solicitação da dotação orçamentária de um ano é composta por uma parcela fixa e outra variável e estocástica, considerada incremental. A parcela fixa é considerada a base orçamentária, significando o resultado de um consenso político no qual estabelece o grau de participação de cada ação no agregado geral. Segundo Barcelos (2008), a base é a garantia da estabilidade dos pilares políticos. Mudanças na base orçamentária, portanto, retratam um novo acordo social. As variações não incrementais podem significar desvios ou mudanças de paradigmas ou de governos (shiftpoints) (SWAIN e Hartley Jr., 2001). Assim, as decisões usualmente são tomadas sobre a parte incremental, podendo apresentar variações lineares ou diferenciadas (BARCELOS, 2008). A existência da base orçamentária implica processos orçamentários sequenciais e repetitivos, o que sugere estabilidade do processo. Esta estabilidade pressupõe que os atores possuem papéis claros e que há confiança em seu comportamento, de modo que as solicitações de dotações, as análises e as autorizações se comportam dentro de padrões estáveis e esperados. Dessa forma, as agências ou órgãos setoriais solicitam acima do necessário, enquanto os órgãos superiores cortam ou concedem valor menor do que o solicitado.

A estabilidade do processo, combinada com a busca por alternativas satisfatórias, faz com que os problemas não sejam analisados todos ao mesmo tempo, e que algumas decisões sejam tomadas de forma fracionada e em momentos distintos, o que permite aos agentes a acumulação de experiência para realizar intervenções com maior segurança (MCCUBBINs e SCHWARTZ, 1987). Os agentes, portanto, recorrem aos mecanismos de análise levantados por March (1994), de decomposição, edição, heurística e simplificação, além de tratar os conflitos por meio de estratégias de alarme de incêndio, o que permite um ganho de atenção (BARCELOS, 2008, p. 429). Dessa forma, o processo orçamentário torna-se mais simples e menos oneroso, o que garante estabilidade positiva e previsibilidade ao modelo (SwaIn e HARTLEY JR., 2001).

Algumas críticas foram levantadas ao modelo proposto por Wildavsky. Barcelos (2008) nota que o incrementalismo é um argumento hostil ao modelo de expectativas racionais e que a análise limitada a um determinado período histórico não garante poder explicativo, além de gerar confusões. Peters (2001) argumenta que o incrementalismo reforça o status quo e não oferece explicação completa das políticas governamentais, além de não ter poder explicativo sobre grandes mudanças em políticas. True (2000) afirma, ainda, que o incrementalismo falha em seu processo explicativo, além de não conseguir diferenciar variações incrementais das não incrementais. Não obstante as críticas, o incrementalismo é considerado como o melhor ponto de partida para os estudos do orçamento público (DAVIS et al., 1966).

\section{Modelo de julgamento serial}

O processo de formulação de políticas públicas é normalmente complexo, envolvendo diversos atores e grupos de interesse, como instituições governamentais, partidos políticos, sociedade organizada, entre outros. Muitas vezes, esses atores agem de forma antagônica, fazendo com que o processo de escolhas eficientes torne-se fundamental. 
O processo de tomada de decisão no contexto orçamentário, em um ambiente de racionalidade limitada, defronta-se com uma nova perspectiva, a partir da abordagem apresentada no trabalho de John Padgett (1980). Cabe destacar que o trabalho de Padget foi influenciado pela obra de Wildavsky e Crecine, e utiliza-se de um modelo de explicação que congrega a complexidade e hierarquia do processo orçamentário numa formulação simples, tentando esclarecer as nuanças do processo orçamentário (GreEn e ThOMPSON, 2001; JONES et al., 1999).

Padgett (1980) trata o orçamento de forma alternativa ao que foi proposto pela teoria incremental de Davis, Dempster e Wildavsky (1966), com a denominação de "teoria do julgamento serial". O modelo pressupõe que as regras de tomada de decisão orçamentárias se baseiam na construção de um processo estocástico, cujo desenvolvimento dos padrões - sob parâmetros homogêneos e heterogêneos de eventos no tempo, geralmente aleatórios, é passível de análise probabilística (JONES et al., 1999).

O modelo de julgamento serial desenvolvido por Padgett se insere no paradigma da racionalidade limitada, diferenciandose do incrementalismo por força da análise sequencial de dados e pela falta de determinismo no resultado final da análise. Tal resultado se deve à ambiguidade, que é incorporada a sua base de resultados (BARBOSA, 2006). Considerando que um conjunto limitado de possibilidades é baseado nas decisões, o problema das escolhas é resolvido em função de alternativas pontualmente ordenadas, em que a opção a ser escolhida será a primeira dita como aceitável (GreEn e Thompson, 2001).

Nesse modelo o tomador de decisão inicia com uma base fixa, toma sua decisão sobre a direção que irá assumir (aumentos ou reduções na alocação orçamentária, diante de uma escolha binária que baliza as subsequentes alternativas relevantes para o tomador de decisões), busca alternativas discretas no orçamento, para em seguida aplicar a teoria do julgamento serial. Partese do pressuposto de que os ciclos decisórios funcionam por meio da análise de alternativas (acréscimos ou decréscimos), até que uma das alternativas encontradas reúna satisfatoriamente aspectos políticos e exigências fiscais, base da teoria do julgamento serial (Swan, 1983).

Ressalta-se que há indicações de que o sistema orçamentário é, muitas vezes, mais responsivo às dinâmicas políticas, burocráticas e técnicas, como proposto pelo modelo seriado, do que sugere a teoria do modelo incremental (PADGETT, 1980).

\section{Modelo de fluxos múltiplos ou MS (Multiple Streams Framework)}

A apreciação do processo de análise de políticas públicas é complementada pelo modelo de fluxos múltiplos (Multiple Streams Framework) desenvolvido por John W. Kingdon, inspirado nos postulados básicos da Teoria das Organizações e no modelo da "lata de lixo" (garbage can) (ZAHARIADIS, 1998), em que os tomadores individuais de decisão atuam em um ambiente de racionalidade limitada, proposto por Simon (1979) e March (1994). O modelo de fluxos múltiplos parte do modelo da lata de lixo, desenvolvido por Cohen, March e Olsen em 1972, e se baseia em expectativas de seleção ou ordenação temporal, em que múltiplos indivíduos (ou grupos) estão envolvidos simultaneamente em muitos eventos, provocando a dispersão da atenção e o sobrecarregamento da agenda por uma complexa gama de oportunidades de escolha, problemas e soluções, 
e relacionando-se em função da proximidade temporal (MARCH, 1994).

Este modelo aborda questões que podem envolver diversos atores, arenas, incentivos, objetivos e interesses, resultando em um processo de decisão de políticas públicas cujas bases são a complexidade dos processos: as incertezas e as ambiguidades (CAVAlCante, 2006). Nesse sentido, o processo de formulação de políticas públicas inclui a maneira pela qual os problemas são conceituados e encaminhados para o governo em busca de soluções, e as instituições governamentais devem formular alternativas políticas (SABATIER, 2007). Dessa forma, para que um problema obtenha a atenção do governo e da classe política dominante, é necessário que o seu entendimento efetue a ligação com uma efetiva solução (Jones et al., 1999).

O modelo considera a construção de uma agenda de prioridades, aliado ao processo de tomada de decisões, e é descrito por três aspectos básicos: o nível de análise ou abrangência, a ambiguidade na elaboração de políticas públicas e a questão da classificação temporal, que se caracteriza pela falta de definição das preferências. Ademais, demonstra como as agendas governamentais são definidas em um ambiente de ambiguidades (falta de clareza) e de competição de posições ontológicas sobre um tema específico, em que as escolhas são realizadas em função do contexto político atual (ZAHARIADIs, 1998).

A base do modelo está centrada na classificação da decisão política em três grandes fluxos ou processos, independentes e separados entre si, porém, com a mesma importância: o fluxo dos problemas, o fluxo das políticas públicas e o fluxo das políticas independentes. A convergência dos três fluxos explica as razões pelas quais alguns problemas são priorizados e inseridos na pauta ou agenda de decisão, enquanto outros são postergados a um segundo plano pelos governos, não constando na agenda de decisão (GOMIDE, 2008).

Outros fatores que determinam o processo político de formação de uma agenda governamental para solução de problemas são a existência de novos atores no processo decisório, a atuação da sociedade organizada e as mudanças no clima organizacional (national mood). Em suma, o processo político ilustra a necessidade de uma conjuntura política para definição das prioridades dos problemas (GOMide, 2008). Consequentemente, o principal desafio do modelo de fluxos múltiplos é indicar o motivo de alguns temas serem debatidos enquanto outros não são, ou seja, como é definida a ordem de prioridades na agenda política.

\section{Equilíbrio pontuado (Terremoto)}

O modelo do equilíbrio pontuado foi inicialmente desenvolvido na área $\mathrm{da}$ biologia, proposta por Niles Eldredge e Stephen Gould em 1972, que abordavam mudanças lentas por um longo período e mudanças bruscas por um período menor em determinados organismos. Esse modelo foi expandido ao contexto das decisões políticas por Baumgarter e Jones (BAumgartner, 2006), no intuito de analisar os processos de decisão aplicáveis aos subsistemas políticos (Jones et al., 1999). O modelo foi construído com o objetivo de explicar os longos períodos de estabilidade com períodos de grandes mudanças e que, por isso, deve-se analisar tanto os elementos que criam estabilidade como também os que ocasionalmente conspiram para mudanças, que podem implicar consequências marcantes do processo (BAUMgartner, 2006).

O modelo estende as teorias de definição de agenda para tratar os momentos 
de estabilidade e incrementalismo e os momentos de significativas mudanças ou mudanças pontuadas (punctuated) (JoNES et al., 1999). Em um contexto de interação organizacional, o modelo de equilíbrio pontuado, além de pressupor decisões sob racionalidade limitada, pretende responder ao fato de determinados assuntos serem debatidos em ambientes restritos, enquanto outros serem incluídos quando da definição das agendas (agenda setting) da macropolítica.

A estabilidade do processo é mantida nos subsistemas de políticas, também denominados de triângulos de ferro ou nichos temáticos, em que os temas são usualmente debatidos por especialistas e onde existe determinada autonomia institucional (monopólios). A macropolítica, por sua vez, é caracterizada por uma agenda de alto nível, e por estar sujeita às pressões políticas (TRUE, 2000), além de ser o fórum de fomento de grandes mudanças, quando os temas saem dos monopólios para serem debatidos nesse novo fórum. A dualidade de um sistema, que mantém a estabilidade e provoca mudanças, decorre do estabelecimento de agendas em um contexto de racionalidade limitada e processamento serial de informações (JonEs et al., 1999).

Relativamente às análises, enquanto a macropolítica utiliza-se de processamento serial de informações, os diversos subsistemas processam vários temas ao mesmo tempo, criando um mecanismo no qual as informações e as alternativas sejam analisadas paralelamente. Diante da impossibilidade de análise de todas as questões na macropolítica, os subsistemas encarregam-se de promover a estabilidade e o incrementalismo. Não obstante, as questões não ficam interminavelmente nos subsistemas, podendo ser alteradas a partir da inclusão na agenda da macropolítica. No entanto, a inclusão na agenda depende da forma pela qual os problemas são formulados e da construção de um novo entendimento, decorrente da interação entre as instituições ou alteração de sua imagem (policy image). Ressalta-se que a inclusão na agenda é pré-requisito para grandes mudanças, embora essas mudanças não sejam garantidas (Jones et al., 1999).

Dessa forma, Jones (1999) afirma que a imagem assume caráter essencial neste modelo, pois pode interferir na definição da

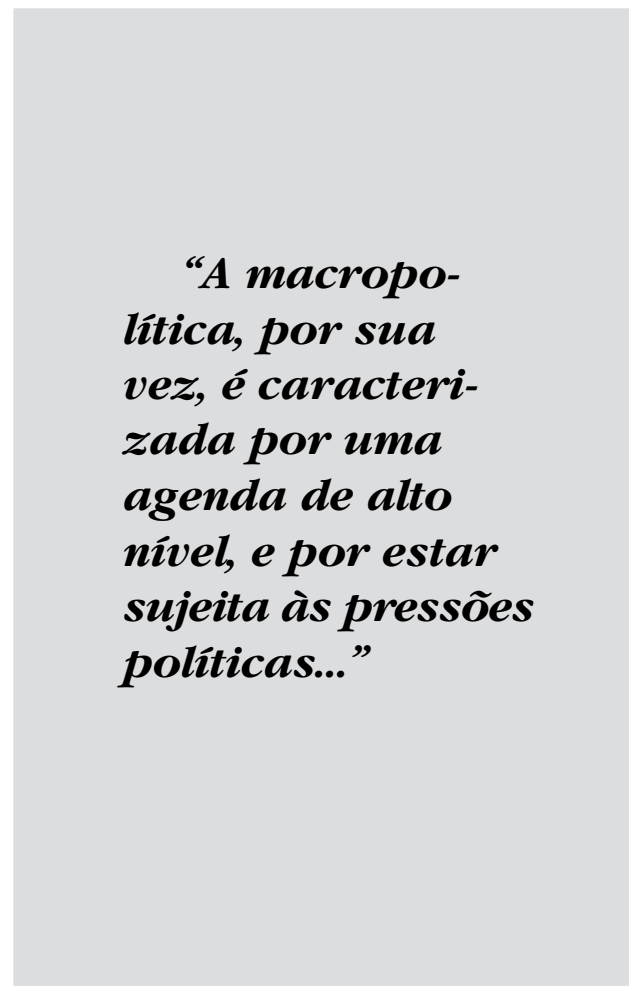

agenda e no processamento de informações. As imagens são uma mistura de informações empíricas e apelos emotivos e sua compreensão pode favorecer o status quo ou, então, as rediscussões (policy venues) (JONES et al., 1999; True, 2000). Na medida em que uma imagem é sólida e reconhecida, ela é associada aos subsistemas considerados monopólios e sujeita às estratégias de 
manutenção e resistência às mudanças (feedback negativo). Por sua vez, imagens fracas implicam manipulação política e exacerbam o impulso às mudanças, inclusive com a participação de novos contextos, novos atores e novas propostas (JONES et al., 1999).

Aplicando o modelo de equilíbrio seriado ao contexto orçamentário, Jones et al. (1999) afirmam que o modelo, denominado terremoto - ao considerar características peculiares de atenção, de definição de agenda e mudanças seriais no processo decisório -, contempla tanto os períodos de estabilidade quanto as grandes mudanças, embora não enfatize mudanças moderadas (Jones et al., 1999). Esse modelo é, portanto, complementar ao incrementalismo (TRUE, 2000). As flutuações ou pontilhados ocorrem em todos os níveis orçamentários por considerar interferências de cima para baixo (top-down) e de baixo para cima (bottomup). Uma característica do modelo terremoto, em relação ao modelo incremental, é o formato leptocúrtico das variações orçamentárias, diferente do formato de sino.
Em suma, o modelo de equilíbrio pontuado aplica-se nos contextos em que os conflitos são expandidos, assim como em outros fóruns que não são apenas os subsistemas. Ademais, ressalta a existência de um fluxo de informações desproporcional, na medida em que o tomador de decisão age de forma branda e, ao mesmo tempo, age como elemento de mudança diante do fluxo de informações dentro do sistema. Não obstante suas vantagens e seu poder de predição dos níveis de estabilidade, não é capaz de ajudar na análise de temas específicos.

\section{Análise de dados}

Deve-se ressaltar que todos os modelos revisitados (incremental, julgamento serial, fluxos múltiplos e equilíbrio pontuado) pressupõem ambiente de racionalidade limitada no processo decisório. Os modelos, portanto, seguem uma sequência lógica, conforme ilustrado na Figura 1:

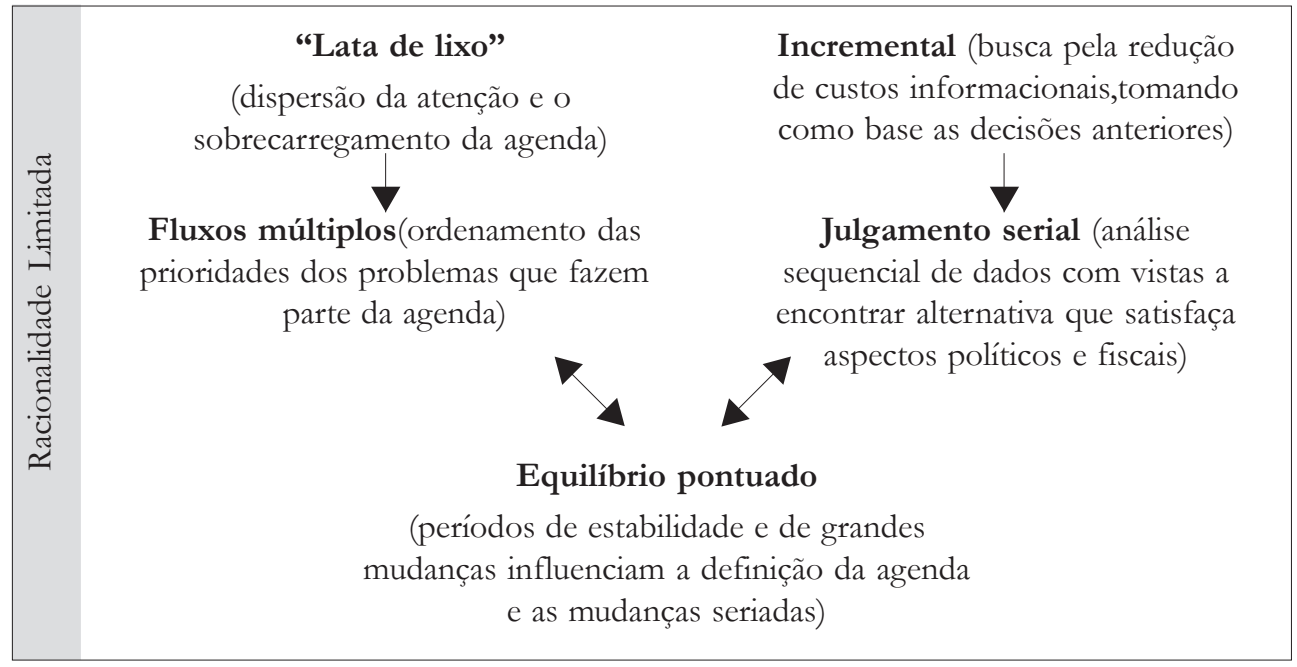

Fonte: Elaboração própria

Figura 1: Fluxo sintético dos modelos incremental, julgamento serial, fluxos múltiplos e equilíbrio pontuado 
Ademais, pode-se afirmar que esses modelos possuem interfaces, bem como diferenças, conforme ilustrado no Quadro 3.
A seguir, serão apresentadas análises de dados sobre as propostas orçamentárias de 2004 a 2010 (encaminhadas pelo Poder

Quadro 3: Análise comparada das características dos modelos de estudos do processo decisório

\begin{tabular}{|c|c|c|c|c|}
\hline Característica & $\begin{array}{l}\text { Incremen- } \\
\text { talismo }\end{array}$ & $\begin{array}{l}\text { Julgamento } \\
\text { serial }\end{array}$ & $\begin{array}{l}\text { Múltiplos } \\
\text { fluxos }\end{array}$ & $\begin{array}{c}\text { Equilibrio } \\
\text { pontuado }\end{array}$ \\
\hline $\begin{array}{l}\text { Processamento } \\
\text { de informações }\end{array}$ & $\begin{array}{l}\text { Serial e } \\
\text { fracionado. }\end{array}$ & Serial & Serial & $\begin{array}{l}\text { Serial, mas com } \\
\text { mudanças de } \\
\text { atenção e em } \\
\text { paralelo nas } \\
\text { subcomissões. }\end{array}$ \\
\hline $\begin{array}{l}\text { Tipo de decisão } \\
\text { e ambiente }\end{array}$ & $\begin{array}{l}\text { Coletivo em } \\
\text { ambiente } \\
\text { organizacional. }\end{array}$ & $\begin{array}{c}\text { Ocorrem sobre } \\
\text { poucas } \\
\text { alternativas } \\
\text { pontuais } \\
\text { ordenadas. } \\
\text { Julgamento } \\
\text { ambíguo. }\end{array}$ & $\begin{array}{c}\text { Escolha } \\
\text { autorizadora a } \\
\text { partir de uma } \\
\text { lista limitada de } \\
\text { alternativas. } \\
\text { Escolhaque } \\
\text { procura fazer } \\
\text { sentido, que } \\
\text { resolve } \\
\text { problemas. }\end{array}$ & $\begin{array}{c}\text { Individual e } \\
\text { coletiva. }\end{array}$ \\
\hline $\begin{array}{c}\text { Elementos e } \\
\text { caracteristicas } \\
\text { essenciais }\end{array}$ & \begin{tabular}{|c|} 
Papéis dos \\
agentes bem \\
definidos \\
(confiança entre \\
os agentes). \\
As variações são \\
consideradas \\
exógenas. \\
Existência de \\
uma base estável.
\end{tabular} & $\begin{array}{c}\text { Análise de } \\
\text { alternativas, até } \\
\text { que uma reúna } \\
\text { satisfatoriamente } \\
\text { aspectos } \\
\text { políticos e as } \\
\text { exigências fiscais. }\end{array}$ & \begin{tabular}{|} 
Seleção em que \\
múltiplos \\
indivíduos (ou \\
grupos) estão \\
envolvidos \\
simultaneamente \\
em muitos \\
eventos.
\end{tabular} & $\begin{array}{c}\text { Busca responder } \\
\text { ao fato de } \\
\text { determinados } \\
\text { assuntos serem } \\
\text { debatidos em } \\
\text { ambientes } \\
\text { restritos } \\
\text { enquanto outros } \\
\text { são incluídos } \\
\text { nas agendas } \\
\text { (agenda setting) } \\
\text { da macropolítica. }\end{array}$ \\
\hline Foco & $\begin{array}{c}\text { Organizacional. } \\
\text { Ambiente } \\
\text { político das } \\
\text { decisões. }\end{array}$ & $\begin{array}{l}\text { Processo } \\
\text { estocástico. }\end{array}$ & $\begin{array}{l}\text { Políticas públicas } \\
\text { em condições de } \\
\text { ambiguidades. }\end{array}$ & $\begin{array}{c}\text { Explicar } \\
\text { variações } \\
\text { incrementais e } \\
\text { grandes variações. }\end{array}$ \\
\hline $\begin{array}{c}\text { Atenção, } \\
\text { agenda e } \\
\text { formato da } \\
\text { curva de } \\
\text { distribuição }\end{array}$ & $\begin{array}{c}\text { Não inclui } \\
\text { definição de } \\
\text { agenda. } \\
\text { Distribuição } \\
\text { formato de sino. }\end{array}$ & $\begin{array}{c}\text { Formação da } \\
\text { agenda de } \\
\text { prioridades para } \\
\text { a tomada de } \\
\text { decisão. }\end{array}$ & $\begin{array}{l}\text { Formação da } \\
\text { agenda } \\
\text { (ordenada por } \\
\text { prioridade). } \\
\text { Ambiguidade. }\end{array}$ & $\begin{array}{c}\text { Imagem provoca } \\
\text { a mudança de } \\
\text { fórum de } \\
\text { discussão, } \\
\text { formato } \\
\text { leptocúrtico. }\end{array}$ \\
\hline $\begin{array}{c}\text { Natureza do } \\
\text { processo } \\
\text { orçamentário }\end{array}$ & $\begin{array}{l}\text { Incremental. } \\
\text { Busca pela } \\
\text { redução de } \\
\text { custos } \\
\text { informacionais } \\
\text { tomando como } \\
\text { base as decisões } \\
\text { anteriores. }\end{array}$ & $\begin{array}{l}\text { Responsivo às } \\
\text { dinâmicas } \\
\text { políticas, } \\
\text { burocráticas e } \\
\text { técnicas. }\end{array}$ & $\begin{array}{c}\text { Construção } \\
\text { de uma agenda } \\
\text { de prioridades } \\
\text { aliada ao } \\
\text { processo } \\
\text { de tomada } \\
\text { de decisões. }\end{array}$ & $\begin{array}{c}\text { Interação política } \\
\text { das instituições, } \\
\text { mobilizações de } \\
\text { interesse e } \\
\text { racionalidade } \\
\text { limitada. }\end{array}$ \\
\hline
\end{tabular}

Fonte: Elaboração própria 
Executivo ao Legislativo), referentes às esferas fiscal e da seguridade social, excluídos pagamentos com amortizações e juros da dívida pública correspondentes aos grupos de natureza de despesas (GND) 2 e 6, atualizados pelo Índice Nacional de Preços ao Consumidor (IPCA) do Instituto Brasileiro de Geografia e Estatística (IBGE).

No tocante ao processo orçamentário brasileiro, verifica-se a contínua elevação das previsões de despesas contidas nas propostas orçamentárias, entre os exercícios de 2004 e 2010 (vide Figura 2), com destaque para o índice de correção $\left(\mathrm{R}^{2}\right)$ de 0,982 para a regressão exponencial da equação resultante: $\mathrm{Y}=491,92 \mathrm{e}^{0,0868 \mathrm{x}}$. A Figura 2 sugere a existência de influências na definição dos valores do orçamento em relação ao ano anterior, o que pode sugerir a verificação de incrementalismo. Não obstante, a verificação pode ser mais bem demonstrada por meio de estudos de correlação ou outros métodos matemáticos.

No entanto, a referida elevação constante dos gastos não se expressou uniformemente para todos os programas, de acordo com o observado na Figura 3, abaixo. Tendo em vista a observação de algumas evoluções das previsões de despesas por programas, com grandes variações nas propostas orçamentárias entre 2004 e 2010, pode-se notar que determinadas agendas políticas representadas por programas tiveram expressivos aumentos, como: Informações Estatísticas e Geocientíficas e Reaparelhamento e Adequação da Marinha do Brasil. Já outras agendas tiveram quedas significativas - Habitação de Interesse Social e Manutenção da Malha Rodoviária Federal. Além disso, há programa com elevações e declínios, tipicamente característico de cíclico - Integração de Bacias Hidrográficas. Tais situações precisam ser pesquisadas para identificação das causas, que provavelmente estão associadas com a formação das respectivas agendas, ressaltadas nos modelos fluxos múltiplos e equilíbrio pontuado.

É fundamental registrar que, embora tenha sido excluído do orçamento público, em 2008, o programa Manutenção da Malha Rodoviária Federal, não significa que todas as ações do programa deixaram de ser feitas, como as atualmente presentes no programa

Valores em bilhões de reais (preços constantes de 2010, atualizados pelo IPCA)

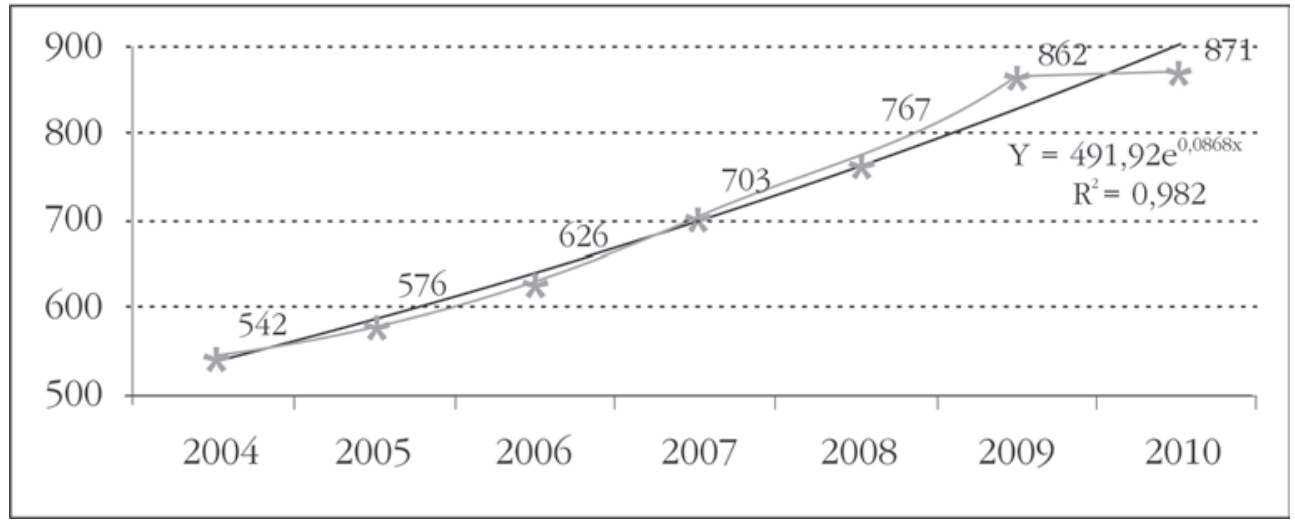

Fonte: Sistema Integrado de Dados Orçamentários (Sidor) - excluída a dívida

Figura 2: Evolução das propostas orçamentárias entre 2004 e 2010 
Vetor Logístico Leste, incluído naquele mesmo ano (vide Figura 3). Ou seja, a exclusão de programas não significa necessariamente descontinuidade, considerando que o governo federal continua mantendo as rodovias sob a sua supervisão. Tais fatos merecem ser mais bem estudados, uma vez que indicam a existência de sinais de mudanças de agenda no âmbito do processo decisório, em que o governo passa a atacar um determinado problema (nesse caso, a manutenção das rodovias federais) sob uma nova perspectiva. Desse modo, considerando que a definição de agenda é relevante para o caso brasileiro, poderiam ser realizados estudos mais aprofundados dessas variações sob as teorias de fluxos múltiplos e equilíbrio pontuado. Igualmente, as Figuras 2 e 3 parecem confirmar a suposição de que o incrementalismo não oferece explicação completa das políticas governamentais, além de não ter poder explicativo sobre grandes mudanças em políticas (JONES et al., 1999; True, 2000).

Em parte, a explicação das grandes variações pode ser justificada pela obser- vação, entre os anos 2004 e 2010, das mencionadas ocorrências de exclusões e inclusões de novos programas no exercício orçamentário, quando comparado com o exercício imediatamente anterior, bem como dos saldos acumulados de exclusões durante os referidos anos (total acumulado no período: 64), significando uma redução de 357 para 293 no período em análise. Tais ocorrências foram maiores no primeiro ano do atual PPA (2008 - 2011), conforme demonstrado na Figura 4, certamente motivadas pelos ajustes da nova agenda política apresentada na eleição de 2006, embora a reeleição presidencial possa gerar expectativas de continuidade dos programas do PPA anterior (2004 - 2007). A descrita conjuntura sugere a necessidade de aprofundamentos dos estudos para responder às seguintes perguntas: como a agenda política influencia as alterações (inclusões e exclusões) de programas no orçamento brasileiro? As citadas alterações significariam a formação de novos acordos sociais? Da mesma forma, necessita-se investigar o papel das avaliações sobre os

Valores em milhòes de reais (preços constantes de 2010, atualizados pelo IPCA)

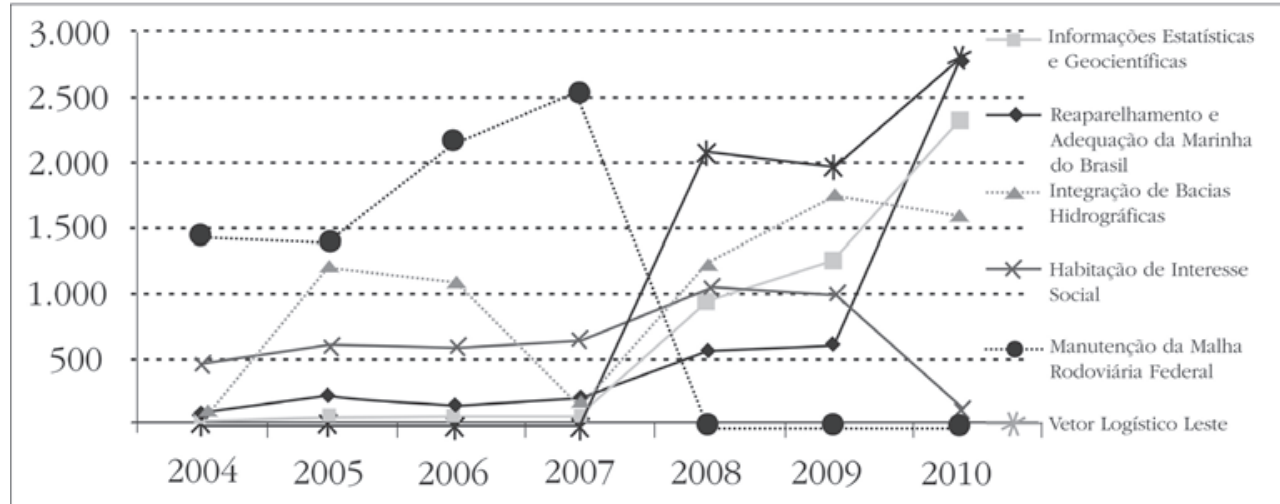

Fonte: Sistema Integrado de Dados Orçamentários (Sidor) - excluída a dívida

Figura 3: Exemplos de evoluções de previsões de despesas, por programas com grandes variações nas propostas orçamentárias, entre 2004 e 2010 
programas e de que forma o processamento das informações está exercendo influência sobre o quantitativo de programas.

No que se refere aos modelos de processos decisórios, outra análise importante relacionada ao processo orçamentário brasileiro, é o comportamento da distribuição das frequências de ocorrência de variações por programas nas propostas orçamentárias, entre os exercícios subsequentes. Nesse sentido, apresenta-se a seguir a Figura 5 com dados de 2004 a 2010, a partir dos quais é possível observar, considerando o formato da curva de distribuição, indícios da existência de características dos modelos incremental e julgamento seriado. Nesse caso, quando

Valores em unidades de programas

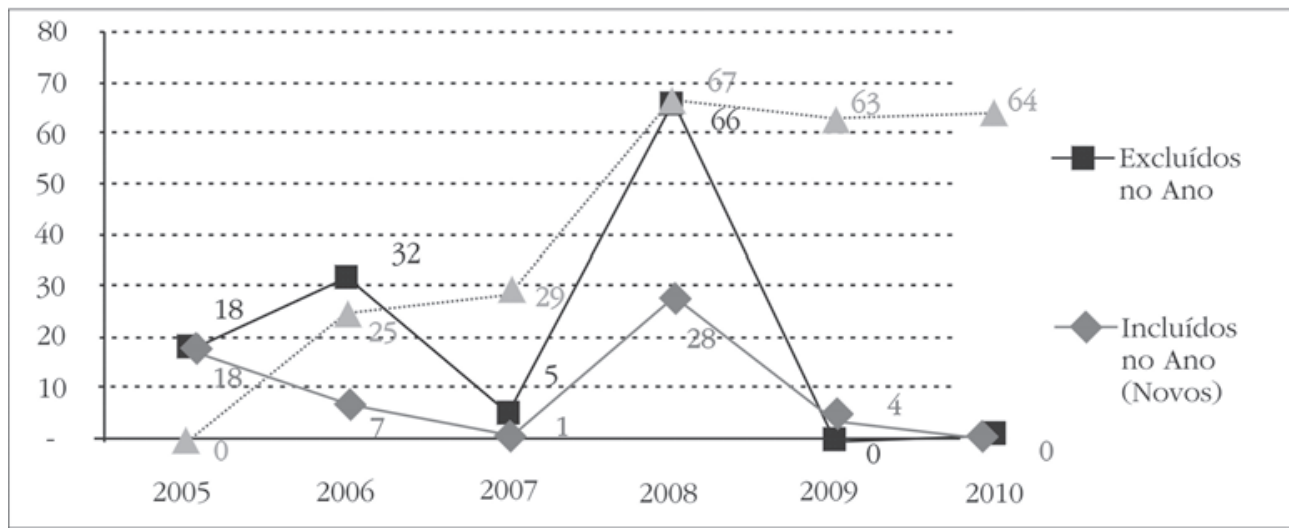

Fonte: Sistema integrado de dados orçamentários (Sidor) - excluída a dívida

Figura 4: Evolução das ocorrências de exclusões, inclusões e saldos de programas no exercício, comparativamente com o anterior, entre 2004 e 2010

Valores em unidades de ocorrências de variações por programas em reais (preços constantes de 2010: atualizados pelo IPCA)

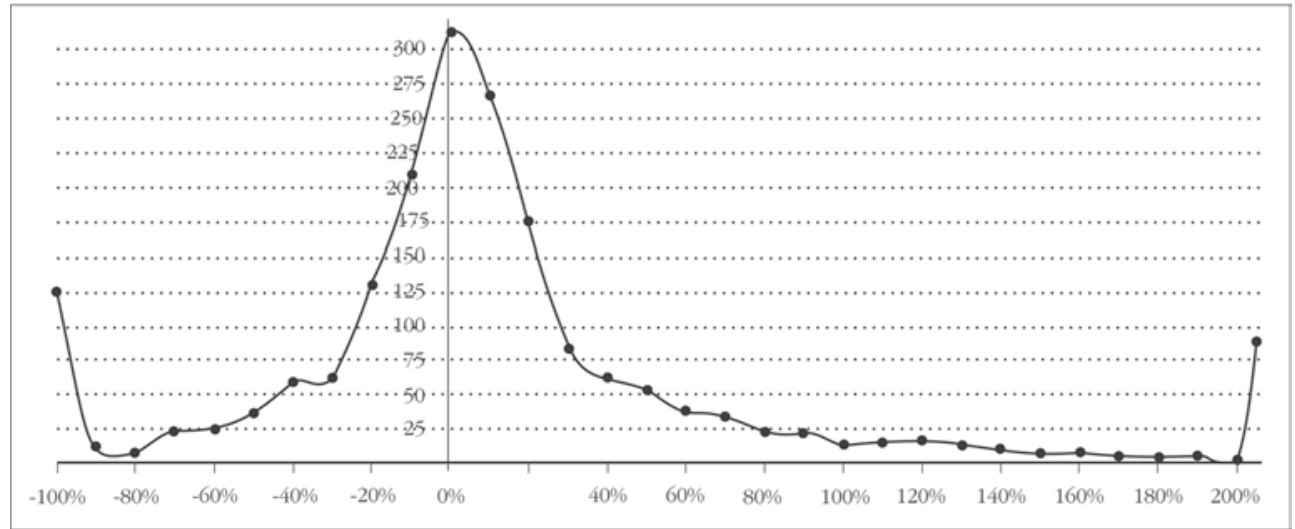

Fonte: Sistema integrado de dados orçamentários (Sidor) - excluída a dívida

Figura 5: Frequência de ocorrências (eixo Y) de variações por programas (eixo $\mathrm{X})$, entre exercícios subsequentes, nas propostas orçamentárias de 2004 a 2010 
observamos a parte central da figura (variações próximas de zero por cento), o formato da curva aproxima-se ao de um sino. É possível identificar, também, características do equilíbrio pontuado (terremoto), pois ao observamos todo o gráfico (inclusive as extremidades) veremos que o formato é leptocúrtico.

Sob a ótica da evolução de citadas variações ao longo dos anos, é fundamental a verificação de que o valor da média das variações - bem como seus respectivos intervalos, com base nos valores de desviopadrão populacional (DP) - foi maior no início das vigências dos PPA em análise (vide Figura 6). Isso reforçaria a possibilidade de a influência política ser mais significativa no início dos governos, o que poderia indicar um processo decisório condicionado por novas agendas políticas, vinculado com as expectativas geradas no período posterior ao pleito eleitoral, fato importante de ser investigado por meio do modelo de fluxos múltiplos.

\section{Considerações finais}

Diante do exposto, infere-se que o modelo incremental está associado à busca da redução de custos informacionais, tomando como base as decisões anteriores (visando ganho de atenção); o julgamento serial tem como princípio a análise sequencial de dados, com vistas a encontrar a alternativa que satisfaça aspectos políticos e fiscais (pressupõe processamento de informação serial); os fluxos múltiplos sob influência do modelo "lata de lixo" concentram-se no ordenamento das prioridades dos problemas que fazem parte da agenda (inclui-se como elemento inovador a definição de agenda); e o equilíbrio pontuado observa que períodos de estabilidade e de grandes mudanças influenciam a definição da agenda e as mudanças seriadas (visão holística).

A partir da análise comparativa dos principais componentes dos modelos em comento, pode-se concluir que todos os

Valores em percentual de variaçoòes por programas em reais (preços constantes de 2010: atualizados pelo IPCA)

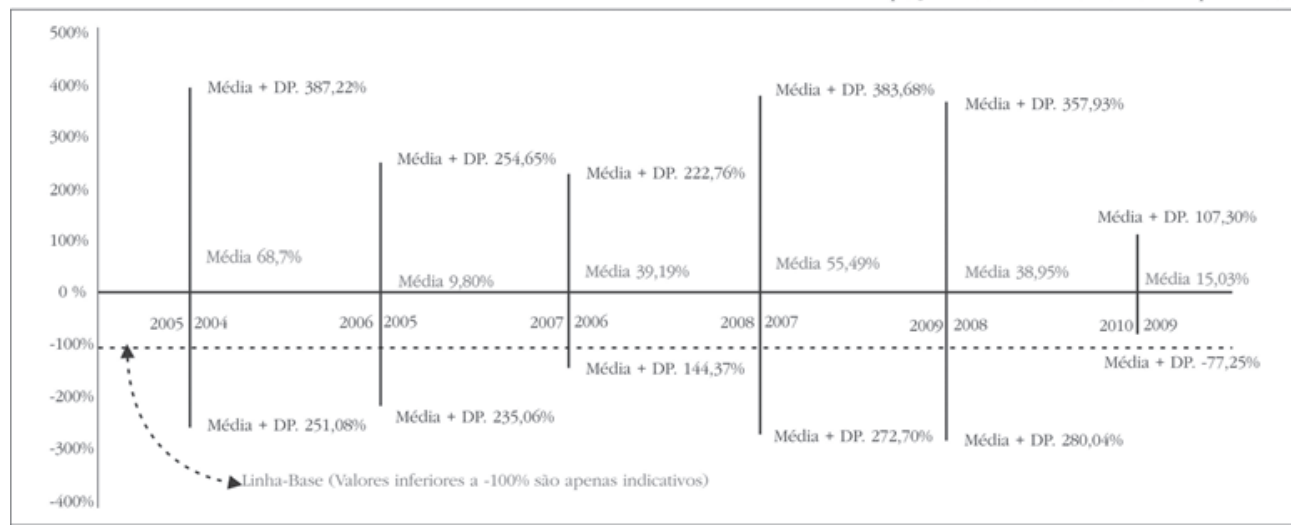

Fonte: Sistema integrado de dados orçamentários (Sidor) - excluída a dívida

Figura 6: Série histórica das médias das variações por programas, entre exercícios subsequentes, nas propostas orçamentárias de 2004 a 2010, com demonstrativo dos intervalos para mais ou para menos do desvio-padrão 
modelos de estudo do processo decisório, objeto deste trabalho, estão contidos em ambientes de racionalidade limitada, sendo que o incremental e o julgamento serial pressupõem regras claras de tomada de decisão orçamentária; ambos se baseiam na construção de um processo estocástico, cujo desenvolvimento dos padrões de eventos é passível de análise estatística, tendo o segundo o diferencial da força da análise sequencial de dados. Os fluxos múltiplos e o equilíbrio pontuado trabalham com a agenda de decisão, sendo que o primeiro está centrado na classificação da decisão política nos fluxos (independentes e separados entre si, porém com a mesma importância) de problemas, políticas públicas e políticas independentes, e o segundo incorpora características peculiares de atenção (base no incremental), de definição de agenda (vínculo com os fluxos múltiplos) e mudanças seriais (associadas com o julgamento serial) no processo decisório.

Partindo da supracitada análise comparada dos modelos em estudo e considerando a apreciação das informações do orçamento federal nos exercícios de 2004 a 2010, apresenta-se, no Quadro 4, agenda de pesquisa para a área de estudos orçamentários no Brasil.

Discriminam-se a seguir algumas questões mais amplas - que poderiam ser trabalhadas com o conjunto dos modelos estudados - sobre os instrumentos atuais do orçamento público brasileiro: não seria a atual configuração do processo orçamentário do PPA elemento motivador para a instabilidade do processo decisório, levando em consideração que ele provavelmente estimula a existência de possíveis ciclos de elevação e diminuições de ocorrências de mudanças de agendas políticas logo no início dos governos, a partir dos compromissos eleitoreiros? Ou seria o PPA um instrumento para legitimação das mudanças desejadas pela sociedade, com relação ao atual status quo governamental? Poderia a LOA, juntamente com a LDO, assumir uma configuração plurianual, com vistas a diminuir a instabilidade no âmbito do processo decisório, promovendo a discussão constante com a sociedade sobre os ajustes futuros desejados para a construção contínua de possíveis agendas governamentais, sem grandes impactos nas variações orçamentárias? Como os instrumentos orçamentários poderiam incorporar uma maior discussão e participação social na elaboração da proposta orçamentária brasileira, de forma a construir mais alternativas que satisfaçam a sociedade?

Concluindo, os modelos de tomada de decisão - incremental, de julgamento serial, de fluxos múltiplos e dos equilíbrios pontuados - estão associados ao processo orçamentário brasileiro, tendo entre eles interfaces, complementaridades e diferenças. A aplicação individualizada desses modelos ou uma combinação deles ao caso brasileiro pode, portanto, enriquecer os debates sobre o tema, assim como trazer grandes benefícios à dinâmica orçamentária, na medida em que o conhecimento mais profundo do tema poderá conduzir a alocações mais eficientes, eficazes e efetivas.

(Artigo recebido em janeiro de 2012. Versão final em maio de 2012). 


\section{Quadro 4: Agenda de pesquisa para a área de estudos orçamentários no Brasil}

\begin{tabular}{|c|c|}
\hline Modelo teórico & Principais temas/questões sugeridos para estudos futuros \\
\hline Incremental & $\begin{array}{l}\text { - Incrementalismo no Orçamento Programa Brasileiro } \\
\text { - A importância da manutenção do status quo das políticas orçamentárias brasi- } \\
\text { leiras sob a perspectiva incremental } \\
\text { - Os ganhos de atenção do orçamento público brasileiro por meio da utilização } \\
\text { de mecanismos de alarme de incêndio } \\
\text { - Estudos de definição de limites para a proposta orçamentária brasileira: uma } \\
\text { visão incrementalista } \\
\text { - As regras, os papéis dos atores, as análises e as autorizações orçamentárias brasi- } \\
\text { leiras se comportam dentro de padrões estáveis e esperados? } \\
\text { - As mudanças orçamentárias no período pós-eleitoral poderiam sugerir a } \\
\text { formação de novos acordos sociais, com impacto sobre a base orçamentária? }\end{array}$ \\
\hline Julgamento serial & $\begin{array}{l}\text { - As decisões seriadas no processo orçamentário brasileiro } \\
\text { - A busca por alternativas orçamentárias brasileiras satisfatórias sob os aspectos } \\
\text { políticos e diante das exigências fiscais } \\
\text { - Os parâmetros homogêneos e heterogêneos das decisões orçamentárias } \\
\text { brasileiras } \\
\text { - Processo decisório orçamentário brasileiro e séries temporais: estudo das } \\
\text { variações orçamentárias pós-RGO } \\
\text { - Como as séries de julgamentos para a decisão estão dispostas no processo } \\
\text { orçamentário brasileiro? } \\
\text { - Como as exigências fiscais influenciam as decisões seriadas no orçamento } \\
\text { brasileiro? Os relatórios bimestrais de avaliação fiscal contribuem para o pro- } \\
\text { - cesso de julgamento seriado? } \\
\text { - Como os stakeholders influenciam o processo decisório orçamentário? }\end{array}$ \\
\hline Fluxos múltiplos & $\begin{array}{l}\text { - A definição da agenda política brasileira e seu reflexo sobre os programas } \\
\text { orçamentários } \\
\text { - A repercussão das variações das agendas no orçamento brasileiro } \\
\text { - Os fluxos de problemas, de políticas públicas e de políticas independentes no } \\
\text { orçamento brasileiro } \\
\text { - Como os pleitos eleitorais podem influenciar a priorização da agenda e } \\
\text { impactam as decisões alocativas nos programas orçamentários brasileiros? } \\
\text { - Quem são os atores e como se comportam? E quais são as arenas, incentivos, } \\
\text { objetivos e interesses da atual política orçamentária brasileira? } \\
\text { - Como podemos diminuir as incertezas e as ambiguidades do processo orça- } \\
\text { mentário brasileiro? }\end{array}$ \\
\hline $\begin{array}{l}\text { Equilíbrio } \\
\text { pontuado }\end{array}$ & $\begin{array}{l}\text { - Grandes mudanças de alocação de recursos orçamentários em curtos períodos } \\
\text { de tempo: inclusões e exclusões de programas e suas relações com a agenda } \\
\text { política } \\
\text { - A estabilidade política do Brasil e suas consequências nas variações qualita- } \\
\text { tivas e quantitativas orçamentárias } \\
\text { - A relevância da autonomia institucional (como estabilizadora) e da macro- } \\
\text { política brasileira (promotora de grandes mudanças) na dinâmica orçamen- } \\
\text { tária brasileira. } \\
\text { - As interferências de cima para baixo (top-down) e de baixo para cima (bottom-up) } \\
\text { nas variações (flutuações ou pontilhados) orçamentárias brasileiras. } \\
\text { - As variações na base orçamentária são reflexos de discussões na macropolítica? } \\
\text { - A adoção de um orçamento plurianual poderia garantir maior estabilidade da } \\
\text { agenda política brasileira? } \\
\text { - As atuais organizações orçamentárias brasileiras são suficientemente fortes } \\
\text { (com imagens sólidas e reconhecidas) para garantir a estabilidade orçamen- } \\
\text { tária brasileira? }\end{array}$ \\
\hline
\end{tabular}

Fonte: Elaboração própria 


\section{Referências bibliográficas}

Abreu, W. M. D. e Gomes, R. C. Orçamento público: análise da formulação de estratégias sob a perspectiva do planejamento emancipatório e desenvolvimentista. Revista do Serviço Público, v. 61, n.3, p. 269-286, jul.-set. 2010.

Abrucio, F. L., e Costa, V. M. F. Reforma do estado e o contexto federativo brasileiro. Pesquisas, 12, p. 1-187, 1998.

Barbosa, L. B. As prioridades fixadas na lei de diretrizes orçamentárias para a administração pública importam? Brasília: Universidade de Brasília, 2006.

BarCelos, C. L. K. Quinze anos sem aaron wildavsky: recordando lições valiosas. Paper presented at the Encontro de Administraçao Pública e Governança, 2008, Salvador - BA. Barcelos, C. L. K., e Calmon, P. C. D. P. A reforma gerencial do orçamento: em busca de múltiplos significados. Paper presented at the XXXIII ENCONTRO DA ANPAD, 2009. Baumgartner, F. R. (2006). Punctuated equilibrium theory and environmental policy. In: Repetto, R. (Ed.). Punctuated equilibrium models and environmental policy. New Haven, CT: Yale University Press.

Bresser-Pereira, L. C. Da Administração Pública Burocrática à Gerencial. Revista do Serviço Público, Brasília, v. 47, jan./abr. 1996.

Cavalcante, P. L. A implementação do orçamento por resultado no âmbito do Executivo federal: um estudo de caso. Brasília: Universidade de Brasília, 2006.

Cohen, M. D.; March, J. G.; and Olsen, J. P. (1972). A garbage can model of organizational choice. Administrative Science Quarterly, 17(1): 1-25.

Core, F. G. Reformas Orçamentárias no Brasil: uma Trajetória de Tradição e Formalismo na Alocação dos Recursos Públicos. IX Congreso Internacional del Clad Sobre la Reforma del Estado y de La Administración Pública, 2004. Madrid, España: CLAD, 2004.

. (2007). Reforma gerencial dos processos de planejamento e orçamento.

In: Giacomoni, J. e Pagnussat, J. L. (Org.). Planejamento e orçamento governamental. Brasília: ENAP. V. 2, p. 219-261.

Dagnino, R. Metodologia de análise de políticas públicas. In: Gestão estratégica da inovação: metodologias para análise e implementação. Taubaté: Editora Cabral Universitária, 2002. Davis, O. A.; Dempster, M. A. H.; e Wildavsky, A. (1966). A theory of the budgetary process. The American Political Science Review, 60 (3): 529-547.

Foscher, A. (2007). "Budget methods and practices". In: Washington, A. S. (Ed.). Budgeting and budgetary institutions. The World Bank, 2007. p. 109-134. (disponível em pdf).

GARCIA, R. C. A reorganização do processo de planejamento do governo federal: O PPA 2000-2003. Texto para Discussão IPEA n. 726. 2000.

Gomide, A. D. A. Agenda governamental e formulação de políticas públicas: o projeto de lei de diretrizes da política nacional de mobilidade urbana. 2008.

Green, M., e Thompson, F. (2001). Organizational models of budgeting. In: Bartle, J. R. (Ed.). Evolving theories of public budgeting. Amsterdam: Elsevier Science. p. 55-83. 
Jones, B. D. (2003). Bounded rationality and political science: lessons from public administration and public policy. Journal of Public Administration Research and Theory, 13(4): 395-412.

Jones, B. D.; Baumgartner, F. R.; e True, J. L. (1999). Punctuated-equilibrium theory: explaining stability and change in public policymaking. In: SABAtier, P. A.(Ed.). Theories of the policy process. $2^{\text {nd }}$. ed. New York: Westview Press. p. 155-187.

Key JR, V. O. (1940). The lack of a budgetary theory. American Political Science Review, 34, dec. 1940.

March, J. G. (1994). A primer on decision making: how decisions happen. New York: The Free Press.

McCubbins, M. D.; Schwartz, T. (1987). Congress: structure and policy. In: McCubBins, M. D.; Sullivan, T. O. (Ed.). Congress: structure and policy. New York: Cambridge University Press. p. 426-438.

Padgett, J. (1980). Bounded rationality in budgetary research. American Political Science Review, 74, p. 354-372.

Peters, B. G. (2001). The Politics of Bureaucracy. $5^{\mathrm{a}}$ ed. London: Routledge.

Sabatier, P. A. (2007). Theories of policies process. Westview Press.

SANChes, O. M. O ciclo orçamentário: uma reavaliação à luz da constituição de 1988. In: Giacomoni, J.; Pagnussat, J. L. (Ed.). Planejamento e orçamento governamental, v. 2, p. 187 217, 2007.

SiLVA, M. D. C. Resenha bibliográfica 1: Budgeting: a comparative theory of budgetary processes. Wildavsky, aaron. Second revised edition. New brunswick (USA) and oxford (uk). Transaction books. Pesquisa e Planejamento Econômico, 18 (1), p. 199-205, 1988.

Simon, H. A. (1979). Rational decision making in business organizations. The American Economic Review, 69(4): 493-513.

Swain, J. W., e Hartley Jr, C. J. (2001). Incrementalism: Old but good? In: BartLe, J. R. (Ed.). Evolving theories of public budgeting. Amsterdam: Elsevier Science. v. 6, p. 11-27.

SwaIN, W. K. (1983). Personality process model organization theory and management. Public administration and public policy, 20.

True, J. L. (2000). Avalanches and incrementalism: making policy and budgets in the United States. The American Review of Public Administration, 30(3).

Zahariadis, N. (1998). Comparing three lenses of policy choice. Policy Studies Journal, 26(3): 434-448. 


\section{Resumo - Resumen - Abstract}

Modelos de tomada de decisão no processo orçamentário brasileiro: uma agenda de pesquisas

Welles Matias de Abreu, Vinícius Mendonça Neiva e Nerylson Lima

Considerando a necessidade de realização de estudos com intuito de melhorar a compreensão dos processos decisórios no setor público, o presente artigo tem como objetivo identificar agenda para pesquisa prioritária e inédita na área orçamentária brasileira, a partir dos principais conceitos dos modelos de estudos do processo decisório incremental, do julgamento serial, dos fluxos múltiplos (MS) e do equilíbrio pontuado (terremoto). A agenda de pesquisa proposta tem como base buscar resposta para a clássica questão levantada por V. O. Key Jr. (1940): “em que base deveria ser decidido alocar X dólares na atividade A em vez da atividade B?" Para tanto, os estudos orçamentários propostos são apresentados em forma de temas e questões a ser objeto de pesquisa no âmbito dos referidos modelos decisórios, relacionados com o processo orçamentário brasileiro.

Palavras-chave: Orçamento público, processo decisório, agenda de pesquisa

\section{Modelos de toma de decisiones en el proceso presupuestario brasileño: una agenda de investigaciones \\ Welles Matias de Abreu, Vinícius Mendonça Neiva y Nerylson Lima}

Teniendo en cuenta la necesidad de realizar estudios para comprender mejor la toma de decisiones en el sector público, este artículo pretende identificar el programa de investigación prioritaria y sin precedentes en el área del presupuesto brasileño, a partir de los conceptos principales de los modelos de estudios del proceso decisorio incremental, del juicio serial, de los flujos múltiples y del equilibrio puntuado (terremoto). El programa de investigación propuesto se basa en la búsqueda por respuesta a la clásica cuestión planteada por V. O. Key, Jr. (1940): "¿isobre qué base debería ser decidido asignar X dólares en la actividad A en lugar de la actividad B?». Para ello, los estudios del proyecto de presupuesto son presentados en forma de temas y cuestiones para investigación en el ámbito de los mencionados modelos de toma de decisiones, en relación con el proceso presupuestario brasileño.

Palabras-clave: Presupuesto público, toma de decisiones, agenda de investigación

\section{Decision making models in the Brazilian Budgetary process: research agenda} Welles Matias de Abreu, Vinícius Mendonça Neiva and Nerylson Lima

Considering the need to conduct studies to better understand the decision-making processes in the public sector, this paper aims to identify the agenda for unprecedented and prioritizing research in the field of Brazilian budgetary processes. This shall be done based on the main concepts of study models for incremental decision-making, serial trial, multiple flows (MS) and punctuated equilibrium (earthquake). The proposed research agenda is focused on the attempt to answer the traditional question raised by V. O. Key Jr. (1940), "On what basis shall it be decided to allocate x dollars to activity A instead of activity B?". For this purpose, the proposed budgetary studies are presented in the form of themes and issues to be the object of research in connection with decision models related to the Brazilian budgetary process.

Keywords: Public budget, decision-making, research agenda 
Welles Matias de Abreu

Mestre em Administração pela Universidade de Brasília (UnB). Analista de Planejamento e Orçamento (APO) e coordenador-geral de Desenvolvimento Institucional da Secretaria de Orçamento Federal (SOF/MP). Contato: wellesmatias@gmail.com

Vinícius Mendonça Neiva

Mestre em Administração pela Universidade de Brasília (UnB). É Analista de Finanças e Controle (AFC) e coordenador na Coordenação-Geral de Desenvolvimento Institucional da Secretaria do Tesouro Nacional (STN/MF). Contato: vinicius.neiva@fazenda.gov.br

Nerylson Lima

Mestre em Administração pela Universidade de Brasília (UnB). É Analista de Finanças e Controle (AFC) e diretor de Administração da Escola de Administração Fazendária (Esaf/MF). Contato: nerylson.silva@fazenda.gov.br 